\title{
Covert bacteriuria in schoolgirls in Newcastle upon Tyne: a 5-year follow-up $\dagger$
}

\author{
NEWCASTLE COVERT BACTERIURIA RESEARCH GROUP $\dagger$ \\ Newcastle General Hospital and Regional Public Health Laboratory, Newcastle upon Tyne
}

SUMmaRY Two hundred and fifty-two schoolgirls with covert bacteriuria were followed up for 5 years. Forty-one girls were prescribed obligatory chemotherapy because of renal involvement, mainly scarring. Of the remaining 211 girls, 106 were randomly allocated to a no chemotherapy group and 105 to a chemotherapy group to receive a 2-year course of chemotherapy. Treatment was highly effective with $98 \%$ showing some response bacteriologically and $90 \%$ being culture-negative at 2 years. However, at 5 years-that is 3 years after stopping treatment-this had fallen to $64 \%$. In the no chemotherapy group $40 \%$ had spontaneously become culture-negative at 2 years and this had increased to $49 \%$ at 5 years. The difference at 5 years between the two groups attains statistical significance. During follow-up, $11 \%$ of the no chemotherapy group and $9 \cdot 5 \%$ of the chemotherapy group developed symptomatic disease of the urinary tract. Renal growth was measured by calculating regression lines for the relationship between kidney length and the distance between the 1 st and 3rd lumbar vertebrae. The rate of growth of the kidneys over 5 years in the two randomised groups was similar. Only one girl (no chemotherapy group) developed a new renal scar during the study. Measurement of the growth rate of individual kidneys in the obligatory chemotherapy group showed that, despite chemotherapy, there was below average growth in 21 out of 33 scarred kidneys and in 8 patients the degree of renal scarring had increased. It was concluded that, when kidneys were radiologically normal, covert bacteriuria did not lead to renal damage or impaired renal growth in the subsequent 5 years, even if it remained untreated. Consequently, it is recommended that schoolchildren should not be screened for covert bacteriuria until a non-radiological method can be devised to detect those with renal scarring.

Chronic urinary tract infection is one of the causes of end-stage renal failure and in Europe is responsible for $21 \cdot 2 \%$ of patients who require dialysis. ${ }^{1}$ It is known that urinary tract infections often start in childhood and even when associated with renal scarring may be fairly asymptomatic. ${ }^{2-4}$ It has therefore been suggested that screening programmes should be instituted to detect covert bacteriuria so that treatment can be started before serious renal damage has occurred. ${ }^{2}$ However before screening programmes can be recommended it must be shown that the natural history of untreated covert bacteri-

$\dagger$ This report should be referred to as the Newcastle Covert Bacteriuria Investigation-Second Report (1980); it was prepared by J B Selkon, C M Roxby, and W Simpson.

††Microbiologists: J B Selkon (co-ordinator), C M Roxby, M S Sprott. Paediatricians: A $R R$ Cain, $G$ Davison, T C Noble. Physicians: $P$ R Uldall, $R$ W Elliott, $M$ Snow. Radiologists: S M Hale, W Simpson. Statisticians: Mr J A Furness, Mrs J Cranage. uria is the progressive development of renal scarring and that this can be prevented by chemotherapy.

With a view to elucidating the natural history of covert bacteriuria 13464 Newcastle schoolgirls aged between 4 and 18 years were screened between 1968 and 1972 for bacteriuria. The findings of the initial screening were reported by the Newcastle Asymptomatic Bacteriuria Research Group in 1975.4 Two hundred and fifty-six $(1.9 \%)$ girls were found to have covert bacteriuria and of 254 who were examined radiologically $39(15 \%)$ had renal scarring. Two girls refused further examinations leaving 252 who were available for follow-up. This report presents the findings of the first 5 years of the follow-up study.

\section{Subjects and methods}

Screening procedure and examination at hospital. Screening was carried out at the schools using a mobile clinic-laboratory. The procedures used were 
described in the previous report. ${ }^{4}$ Any girl with a bacterial count of $10^{5}$ organisms per $\mathrm{ml}$ in at least 2 of the 3 specimens was considered to have significant bacteriuria and was referred to hospital. Any child with a history of urinary tract infection which had been diagnosed during a previous referral to hospital was excluded. A routine examination was carried out; this included measurements of height, weight, and blood pressure. Six midstream specimens of urine were collected at weekly intervals and an intravenous urogram (IVU) and a micturating cystourethrogram (MCU) was carried out as previously described.

Radiology. All 252 girls in the follow-up study had an IVU and all but 2 also had an MCU. The intention was to have an IVU on all and an MCU when clinically deemed essential at the 2- and 5-year follow-up. For various reasons, the timetable of follow-up examinations was not strictly adhered to (the 10-day rule imposed problems with some of the older girls). As a result, only $55 \%$ of the first reviews were between 1 year 10 months and 2 years 3 months, and only $51 \%$ of the second reviews were between 4 years 10 months and 5 years 3 months.

The same features were searched for on the review IVUs as in the initial survey: evidence of scarring in the kidneys and dilatation of the urinary tract. The lengths of the kidneys and the distance between the 1 st and 3rd lumbar vertebrae were measured, to allow comparisons of growth of the kidney using the technique of Eklöf and Ringertz. ${ }^{5}$ The reason for introducing this measurement instead of simply correlating kidney length with time, as done by the Cardiff-Oxford Bacteriuria Study Group in $1978{ }^{6}$ was because many of the girls in the present study were older and had stopped growing during the follow-up period.

Classification. The 252 girls were divided initially into two groups. The first consisted of 39 girls considered to have renal involvement at initial assessment. This comprised radiologically demonstrable renal scarring (30 girls), excessive pyuria defined as $>0.05 \times 10^{9} / 1$ leucocytes in each of 6 specimens collected at hospital (8 girls), and a history suggesting acute pyelonephritis (1 girl). Two other girls with severe ureteric reflux (grade 4) were included in this group, bringing the total to 41 . One girl with gross bilateral renal scarring and hydronephrosis had papilloedema, hypertension (180/ $120 \mathrm{mmHg}$ ), and a blood urea level of $7.5 \mathrm{mmol} / 1$ $(45 \mathrm{mg} / 100 \mathrm{ml})$. All the other girls were normotensive and had normal blood chemistry. For ethical reasons, it was agreed that these girls should be given chemotherapy, and they were classified as the obligatory chemotherapy group (OCG).

The remaining 211 girls were randomly allocated (using sealed envelopes) into two groups; a chemotherapy group (CG, $\mathrm{n}=105$ girls) to be given routine chemotherapy as detailed below, and a no chemotherapy group (NCG, $\mathrm{n}=106$ girls) who were to remain untreated unless symptomatic urinary tract disease or other infective illness demanded antibacterial treatment. Included in the 211 girls were 16 who had equivocal or minimal scarring, 35 who had reflux, and 9 who had duplication. None of the 211 girls had hypertension or a raised blood urea level.

Follow-up. All girls were seen at about 3 and 6 months after the first investigations, and then at intervals of 6 months, extended in some to 12 months after 2 years. At each visit height, weight, and, in most cases, blood pressure was recorded and a midstream specimen of urine was obtained for bacteriological examination. A further specimen was collected within the week. The girls were asked about symptoms which might suggest urinary tract disease. They were also asked about visits to their GP and what treatment, particularly antibiotics, had been prescribed. At the 2-year and 5-year visits arrangements were made for the IVU to be repeated. Owing to the distress caused to many of the girls by micturating cystography, this examination was repeated only at the discretion of the clinician. When each IVU was being performed, blood was collected for urea estimation and serum antibody titre to the infecting organism. ${ }^{7}$

\section{No chemotherapy group}

If at any time during follow-up a girl developed symptoms suggesting urinary tract infection, and these were supported by appreciable positive cultures, a 10-day course of an appropriate antibiotic was prescribed. In addition, a small number of girls developed symptoms or radiological features suggesting progressive renal disease. They were investigated thoroughly and long-term chemotherapy was prescribed if thought appropriate.

\section{Chemotherapy group}

Each girl in this group was given a 2-year course of an antibiotic depending on the drug-sensitivity of the organism. If choice was possible, co-trimoxazole was the drug used (daily dose of $4 \mathrm{mg} / \mathrm{kg}$ trimethoprim with a maximum of $160 \mathrm{mg}$ per day) for 3 weeks, followed by sulphadimidine $(40-50 \mathrm{mg} / \mathrm{kg}$ with a maximum daily dose of $2.0 \mathrm{~g}$ ). Other drugs prescribed were, in order of preference, nalidixic acid $(40 \mathrm{mg} / \mathrm{kg}$ per day, maximum $2.0 \mathrm{~g}$, reducing to 
20-30 mg/kg per day after 3 weeks), ampicillin $(40 \mathrm{mg} / \mathrm{kg}$, maximum $2 \cdot 0 \mathrm{~g}$, reducing to $20-30 \mathrm{mg} /$ $\mathrm{kg}$ ), and nitrofurantoin $(5-8 \mathrm{mg} / \mathrm{kg}$, maximum $200 \mathrm{mg}$, reducing to $2-3 \mathrm{mg} / \mathrm{kg}$ ). Chemotherapy was changed if resistant organisms emerged or side effects developed.

Treatment was stopped after 2 years provided it had been effective during the previous 6 months. If further infection was demonstrated at subsequent follow-up examinations by finding a significant number of bacteria in two specimens, chemotherapy was prescribed if thought to be necessary on clinical grounds.

\section{Obligatory chemotherapy group}

Chemotherapy was given initially for 2 years as in the CG. The situation was then reviewed and a decision reached as to whether it should be continued or stopped, depending on bacteriological, radiological, and clinical findings. Similar decisions were made in the succeeding years.

\section{Results}

\section{Bacteriological follow-up.}

No chemotherapy group

Of the 106 girls allocated randomly to the NCG, 13 were prescribed chemotherapy by their GPs before their first hospital visit. Eight of these girls still had positive urine cultures when they attended

Table 1 Spontaneous remission during the 5-year follow-up period of 100 girls in the no chemotherapy group

\begin{tabular}{llll}
\hline $\begin{array}{l}\text { Follow-up } \\
\text { visit to } \\
\text { hospital }\end{array}$ & $\begin{array}{l}\text { Number becoming and } \\
\text { remaining culture-negative } \\
\text { at each visit }\end{array}$ & $\begin{array}{l}\text { Cumulative total of } \\
\text { girls in remission }\end{array}$ \\
\cline { 2 - 4 } & & No & $(\%)$ \\
\hline 1st visit & 5 & 5 & $(5)$ \\
3 months & 7 & 12 & $(12)$ \\
6 months & 3 & 15 & $(15)$ \\
1 year & 7 & 22 & $(22)$ \\
2 years & 4 & 26 & $(26)$ \\
3 years & 7 & 33 & $(33)$ \\
4 years & 9 & 42 & $(42)$ \\
5 years & 6 & 48 & $(48)$ \\
\hline
\end{tabular}

hospital and therefore it was considered that the chemotherapy had had no effect on the natural history of their bacteriuria and they were retained in the NCG. However, the remaining 5 had culturenegative specimens for at least 4 years thereafter and have therefore been excluded from the 5-year bacteriological assessment of the NCG. A further girl was excluded because she was followed up for only 6 months, leaving 100 of the original girls allocated to this group.

The cumulative percentage of girls at each visit who became and remained thereafter culturenegative in the absence of chemotherapy is shown in Table 1. The month of conversion was taken as the first hospital visit at which negative cultures were obtained. Forty-eight of the 100 girls in the NCG were in remission by the fifth year of follow-up. None of these girls had been prescribed antimicrobial chemotherapy for any reason during the 5-year period. However, among the 52 girls remaining, 23 had been given antibiotics at some time during the follow-up period, either for symptomatic infections affecting the urinary tract, or for other incidental infections requiring a short course of treatment (Table 3). One girl, who was given a week's course of ampicillin for symptoms suggesting cystitis, but was culture-negative before and after treatment and remained negative for the remainder of the 5 years, should probably also be included in the spontaneous remission group which would then be 49 .

Table 2 shows the results of the bacteriological follow-up of the 23 girls in the NCG who received treatment at some time during the 5-year follow-up period.

The proportion of girls who were culture-negative at 5 years was related to the age of the girl on admission to the study. The rate of remission in the 18 girls aged 4 to 7 years was $27.8 \%$, in the 49 aged 8 to 11 it was $57.1 \%$, and in the 33 aged 12 to 18 years it was $45.5 \%$. These differences do not attain statistical significance.

The proportion of girls who were culture-positive at the different follow-up examinations is shown in the Figure in comparison with the girls in the CG. At 2 years $60 \%$ were culture-positive, and at 5 years $49 \%$ were culture-positive.

Table 2 Bacteriological results in girls given chemotherapy during follow-up who had been allocated to the no chemotherapy group

\begin{tabular}{|c|c|c|c|c|c|}
\hline \multirow[t]{2}{*}{ Total } & \multirow[t]{2}{*}{$\begin{array}{l}\text { Culture-negative before } \\
\text { and after chemotherapy }\end{array}$} & \multirow[t]{2}{*}{$\begin{array}{l}\text { No remaining culture-negative } \\
\text { after stopping chemotherapy }\end{array}$} & \multicolumn{2}{|c|}{$\begin{array}{l}\text { Responded to treatment but } \\
\text { became culture-positive after } \\
\text { chemotherapy stopped }\end{array}$} & \multirow[t]{2}{*}{$\begin{array}{l}\text { Persistently positive } \\
\text { cultures or continuing } \\
\text { chemotherapy }\end{array}$} \\
\hline & & & Asymptomatic & Symptomatic & \\
\hline 23 & 1 & 10 & 1 & 3 & 8 \\
\hline
\end{tabular}




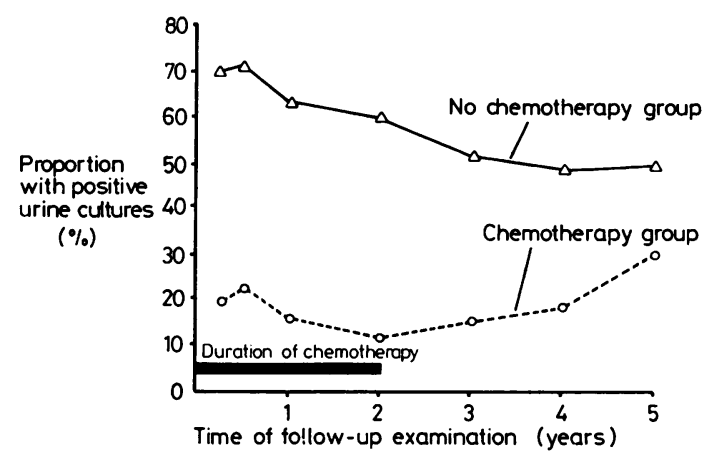

Figure Proportion of girls in the two randomised groups with culture-positive midstream urine specimens during the 5-year follow-up.

\section{Chemotherapy group}

The girls allocated to this group were all prescribed antibiotics for at least 2 years after the start of the study. This group was studied to find out how many girls remained culture-negative after stopping chemotherapy, and how many relapsed or remained culture-positive despite treatment. Of the 105 girls allocated to this group, 6 were followed up for 2 years or less, and were therefore excluded from this particular analysis, leaving a total of 99 girls. During treatment 97 of the 99 girls showed some response to treatment with a series of negative cultures but in 10 the response was variable, probably because of poor compliance, and urine cultures were intermittently positive. As shown in the Figure, $9(10 \%)$ were culture-positive at 2 years and 36 $(36 \%)$ at 5 years. Of the 36 who were culturepositive at 5 years, 26 had remained asymptomatic and 10 had developed symptoms. Only 2 girls remained persistently culture-positive.

Obligatory chemotherapy group

Of the $\mathbf{4 1}$ girls in this group, 2 were followed up for less than 5 years and were excluded from this analysis. Of the remaining 39 girls, $17(44 \%)$ remained consistently culture-negative after stopping treatment. Eight girls relapsed after stopping chemotherapy but 4 responded to a further course of treatment and were culture-negative by the fifth year. Twelve girls who were still receiving chemotherapy by the fifth year were culture-negative. Two girls showed little response to chemotherapy. Thus at 5 years, $33(85 \%)$ of the 39 girls were culturenegative and $6(15 \%)$ were culture-positive.

Symptomatic disease of the urinary tract and other conditions which required chemotherapy. The occurrence of symptomatic disease was compared in the two randomised groups of girls during the 5-year follow-up period.

Of the 100 girls remaining in the NCG, $11(11 \%)$ eventually required treatment for symptomatic disease of the urinary tract (Table 3), comprising 5 girls with clinically diagnosed acute pyelonephritis, 4 with cystitis, 1 with frequency, and 1 with haematuria. A further 4 girls were prescribed chemotherapy for excessive pyuria, 2 for enuresis, and 2 for poor kidney growth; poor kidney growth was not confirmed on subsequent analysis. In addition, 5 girls received chemotherapy for conditions unrelated to the urinary tract-such as tonsillitis, toothache, vulvovaginitis, a style, and one was given treatment in error. None of the girls developed hypertension or a rise of blood urea concentration.

In the CG, which consisted of 105 girls, 10 developed symptomatic disease of the urinary tract (Table 4), 4 within the 2-year treatment period, and 6 after they had stopped treatment. In 3 of the girls, a clinical diagnosis of acute pyelonephritis was made and 7 had symptoms of lower urinary tract infection. A further 5 girls had illnesses requiring treatment which were unrelated to the urinary tract: tonsillitis (in 4) and a chest infection (in 1). None of the girls developed hypertension or a rise of blood urea concentration.

Table 3 Girls allocated to no chemotherapy but subsequently prescribed chemotherapy, and incidence of symptomatic disease

\begin{tabular}{|c|c|c|c|c|c|c|c|c|c|}
\hline $\begin{array}{l}\text { Approximate } \\
\text { time of onset } \\
\text { of symptoms }\end{array}$ & $\begin{array}{l}\text { Clinically acute } \\
\text { pyelonephritis }\end{array}$ & $\begin{array}{l}\text { Symptoms } \\
\text { suggesting lower } \\
\text { urinary tract } \\
\text { infection }\end{array}$ & Pyuria & Frequency & Haematuria & Enuresis & $\begin{array}{l}\text { Poor kidney } \\
\text { growth }\end{array}$ & Other & Total \\
\hline $\begin{array}{l}3 \text { months } \\
6 \text { months } \\
1 \text { year }\end{array}$ & $\begin{array}{l}1 \\
2 \\
1\end{array}$ & & $\begin{array}{l}1 \\
1\end{array}$ & 1 & 1 & & & $\begin{array}{l}1 \text { toothache } \\
1 \text { tonsillitis } \\
1 \text { vulvovaginiti }\end{array}$ & $\begin{array}{l}3 \\
3 \\
5\end{array}$ \\
\hline $\begin{array}{l}2 \text { years } \\
3 \text { years } \\
4 \text { years } \\
5 \text { years }\end{array}$ & 1 & $\begin{array}{l}1 \\
1 \\
1 \\
1\end{array}$ & 1 & & & 2 & $\begin{array}{l}1 \\
1\end{array}$ & $\begin{array}{l}1 \text { stye } \\
1 \text { in error }\end{array}$ & $\begin{array}{l}5 \\
5 \\
1 \\
1\end{array}$ \\
\hline
\end{tabular}


Table 4 Occurrence of symptomatic disease in the chemotherapy group $(n=15)$

\begin{tabular}{llll}
\hline $\begin{array}{l}\text { Approximate } \\
\text { time of onset } \\
\text { of symptoms }\end{array}$ & $\begin{array}{l}\text { Clinicallyacute } \\
\text { pyelonephritis }\end{array}$ & $\begin{array}{l}\text { Symptoms of } \\
\text { lower urinary } \\
\text { tract infection }\end{array}$ & Others \\
\hline 3 months & 2 & 3 (2 tonsillitis) \\
6 months & 1 & 1 (chest infection) \\
$\begin{array}{l}1 \text { year } \\
2 \text { years }\end{array}$ & $\begin{array}{c}\text { (but with } \\
\text { negative urine) }\end{array}$ & \\
$\begin{array}{l}3 \text { years } \\
4 \text { years }\end{array}$ & 2 & 1 (tonsillitis) \\
5 years & 2 & 2 & \\
\hline
\end{tabular}

Radiological comparison of the chemotherapy and no chemotherapy groups. Radiographic measurements were available for analysis on 91 girls in the CG and 92 in the NCG. Follow-up data were available for 173 at 2 years and for 112 at 5 years. Thus information was available potentially from 468 radiographs. In order to determine whether there was evidence of restricted growth of the kidneys in the girls who had received no treatment, a regression line was calculated for the relationship between kidney length and the distance between L1 and L3. This was done separately for right and left kidneys. These lines contained information derived from the lengths of the kidneys at the start of the trial and at follow-up examinations. If growth had been restricted a different slope for this regression line would have been expected in the affected group. However, as shown in Table 5, there was no significant difference between the slopes of the CG and the NCG.

This analysis of fairly large numbers could have obscured a small subgroup of girls who might not have progressed satisfactorily, but whose numbers were too few to affect the overall picture. A number of further analyses was therefore undertaken: (1) 41 girls (Table 6) had radiological abnormalities at the start of the trial. There were slightly more of them in the NCG than in the CG, but the difference between the two fell short of statistical significance. After excluding these girls, regression lines were again calculated for right and left kidneys from the data obtained at the start of the trial and at 2 and 5 years of follow-up. Comparison between the CG and NCG again showed no statistically significant difference. (2) The growth of the kidneys of the girls with some radiological abnormality was analysed separately. Eklöf and Ringertz $z^{5}$ discovered the relationship between kidney length and L1-L3. Their paper gives a line of best fit which can be expressed as:

Kidney length $(\mathrm{mm})=0.98(\mathrm{~L} 1-\mathrm{L} 3) \mathrm{mm}+26 \mathrm{~mm}$ with a standard deviation of $7 \cdot 25 \mathrm{~mm}$.

We had hoped to use this but we found a significantly different $(P<0 \cdot 0001)$ line for the pooled data of girls with no radiological abnormality. Our regression line was:

Kidney length $(\mathrm{mm})=0.66(\mathrm{~L} 1-\mathrm{L} 3) \mathrm{mm}+50 \mathrm{~mm}$ with a standard deviation of $6.7 \mathrm{~mm}$.

This was statistically very significant $(P<0.00001)$. We can only assume that the difference between these two lines represents an unexplained difference between the populations or methodology. It seems unlikely that the difference was the result of our children having bacteriuria, whereas their population was a truly normal one. Also, a paper from Sweden by Claësson and Lindberg, ${ }^{8}$ for schoolgirls with

Table 5 Comparison of the regression lines between the chemotherapy and no chemotherapy groups

\begin{tabular}{|c|c|c|c|c|c|}
\hline \multirow[t]{2}{*}{ No } & \multirow[t]{2}{*}{ Chemotherapy group } & \multirow[t]{2}{*}{ No } & \multirow[t]{2}{*}{ No chemotherapy group } & \multicolumn{2}{|l|}{ Comparisons } \\
\hline & & & & Of gradients & Of intercepts \\
\hline 212 & $\begin{array}{l}\text { Right kidneys } \\
\mathrm{y}=(0 \cdot 66 \pm 0 \cdot 02) \mathrm{X}+(48 \cdot 6 \pm 2 \cdot 5) \\
\text { Left kidneys }\end{array}$ & 214 & $y=(0 \cdot 74 \pm 0 \cdot 03) X+(41 \cdot 7 \pm 3)$ & NS $(t=1 \cdot 89)$ & NS $(t=1 \cdot 72)$ \\
\hline 211 & $y=(0.66 \pm 0.03) X+(51.0 \pm 3)$ & 209 & $y=(0.69 \pm 0.03) x+(48.9 \pm 3)$ & NS & NS \\
\hline
\end{tabular}

$y=$ kidney length, $X=$ L1-L3. NS = not significant.

Table 6 Changes in kidney length compared with L1-L3 on follow-up: initially abnormal kidneys or reflux

\begin{tabular}{|c|c|c|c|c|c|c|}
\hline \multirow[t]{2}{*}{ Initial abnormality } & \multicolumn{3}{|l|}{ Chemotherapy } & \multicolumn{3}{|c|}{ No chemotherapy } \\
\hline & Deteriorated & Unchanged & Improved & Deteriorated & Unchanged & Improved \\
\hline $\begin{array}{l}\text { Scar } \\
\text { Reflux } \\
\text { Duplication }\end{array}$ & $\begin{array}{l}1 \\
0 \\
0\end{array}$ & $\begin{array}{l}2 \\
9(2 D) \\
5(2 R)\end{array}$ & $\begin{array}{l}0 \\
0 \\
0\end{array}$ & $\begin{array}{l}0 \\
3(2 D) \\
2(2 R)\end{array}$ & $\begin{array}{r}6(3 R) \\
16(3 S) \\
3(1 S)\end{array}$ & $\begin{array}{l}0 \\
1 \\
0\end{array}$ \\
\hline Any abnormality & 1 & 14 & 0 & 4 & 21 & 1 \\
\hline
\end{tabular}

Brackets indicate combined abnormalities-for example (3S) = 'includes 3 with scars', $\mathbf{R}=$ 'reflux', D = 'duplication'.

'Unchanged' includes any increase or decrease in kidney size relative to L1-L3 falling within 1 standard deviation. 
covert bacteriuria confirmed the Eklöf and Ringertz line. This problem is discussed in a separate paper. ${ }^{15}$ We have therefore used our own line for children with normal radiological appearances to study the progress of children with abnormalities. The cases are summarised in Table 6 and show very little difference between the progress of the kidneys which were initially scarred, duplicated, or associated with reflux in either the CG of the NCG when compared with the normal group. The ratio of the kidney length to L1-L3 remained within one standard deviation of its starting point in the majority. Follow-up showed only one girl below this range in the CG and 4 in the NCG. This was offset by one in the NCG apparently improving beyond this range.

As there was a wide age range on admission to the study, renal growth was examined separately for girls on admission aged 4 to 9 years, 10 to 14 years, and 15 to 18 years. Comparisons of the CG and NCG in these age ranges again showed no differences in the regression lines.

Finally we looked for morphological evidence of change. There was only one girl who developed an unequivocally new scar in a previously normal kidney. She had grade 2 reflux (up to the affected kidney but without distension) on the affected side and she was initially placed in the NCG. At the 3-month assessment she showed excessive pyuria $(>0.05 \times$ $10^{9} / 1$ leucocytes) and was prescribed long-term sulphonamides. She initially responded bacteriologically but relapsed with resistant organisms, and her IVU at 2 years showed the presence of moderate scarring in the upper zone of the right kidney. At the 5 -year assessment there was no further extension of scarring. Reflux was still present on this occasion producing distension of the upper urinary tract. Another girl showed progression of a pre-existing scar. She had no reflux and was in the CG. Only 3 girls in the CG and 7 in the NCG with reflux had repeat MCUs. The reflux had disappeared in 5 (4 NCG).

Radiological results of the obligatory chemotherapy group. Complete radiological follow-up was carried out in $\mathbf{3 3}$ girls. The majority had renal scarring to a greater or lesser degree, which was bilateral in 6 . Only 6 girls had normal kidneys on both sides. The scarring increased in 8 patients during follow-up, and decreased in 3 . When the growth of individual kidneys was measured, 21 scarred kidneys out of 33 examined showed poor growth $(>1$ standard deviation) compared with only 3 out of 33 normal kidneys.

There was a suggestion that renal deterioration was more common in girls with persistent reflux in addition to renal abnormalities, although the numbers were small; 7 out of 8 girls with reflux showed increased renal involvement, compared with 11 out of 25 girls with renal abnormalities but no reflux, or where reflux had cleared on subsequent examination. Thirteen girls who had initially had reflux were re-examined at either 2 or 5 years. In 6 it had cleared completely, in 3 it had cleared unilaterally only, and in 4 it persisted.

None of the girls in this group became hypertensive or developed abnormal blood chemistry during the follow-up period. The one girl who initially had malignant hypertension responded well to reimplantation of the ureters and chemotherapy.

Results of serum antibody titre estimations. A venous blood sample was taken at each attendance for IVU in order to estimate the titre of serum antibodies to the infecting organisms isolated initially and during the follow-up period. All but one of the girls had one such estimation, the majority having 2 or 3 samples of blood examined.

In our previous paper ${ }^{4}$ we reported a correlation between a high titre of agglutinating antibody ( 1 in 320 or above) and the presence of renal scarring. High levels of antibody were found in $18(47 \%)$ of the 38 girls with renal scarring who were tested, compared with $30(17 \%)$ of the 170 without scarring. When the blood samples taken during follow-up were included 5 further girls with renal scarring developed titres of 1 in 320 or more, thus bringing the total to $23(60 \%)$ of the 38 girls with scarring who were tested. Thirteen girls without scarring, whose initial titre of antibodies was low also developed a high titre later, bringing their total to $43(25 \%)$ of the 170 tested.

\section{Discussion}

One of the main aims of this study was to obtain information about the natural history of covert bacteriuria and to determine whether or not chemotherapy had any beneficial effect.

Although chemotherapy was highly successful, as shown in the Figure, in controlling the urinary tract infection and $91 \%$ of the CG were culture-negative at 2 years, the ultimate result was less satisfactory and only $64 \%$ were still culture-negative at the 5 -year assessment-that is 3 years after stopping chemotherapy. In the NCG, an increasing number of girls became culture-negative spontaneously, $26 \%$ being in remission by 2 years, and $48 \%$ by 5 years. The difference between the NCG and the CG at 5 years is significant $(P<0.05)$, but represents a fairly minor long-term advantage of a 2-year course of chemotherapy. It could be argued that a 
more-prolonged period of chemotherapy might have increased the proportion who remained culturenegative 3 years after stopping treatment. However, a 2-year course was chosen because it was thought to be the maximum that could be maintained in an essentially asymptomatic population. In this respect it must be stressed that all our statements regarding treatment refer to drugs prescribed. We believe that most of the girls received the antibiotics prescribed, but there is good evidence, supplied in some cases by the girls' mothers, that a small number took their drugs irregularly, or failed to take them. This was to be expected from a survey on an essentially healthy population. On the other hand, we do not think that any of the girls received antibacterial agents which were not recorded.

A comparison of the development of symptomatic disease of the urinary tract between the CG and NCG failed to demonstrate any significant difference, 10 girls in the former group and 11 in the latter having developed symptoms. However, a further 5 girls in the NCG were prescribed chemotherapy because of clinical evidence suggesting renal involvement: pyuria (in 3), and poor renal growth (in 2) which was not confirmed on subsequent examinations. Antibiotics were also prescribed for 2 girls because of continuing enuresis.

It was important to determine whether the treatment of girls with covert bacteriuria had any effect on the growth rate of the kidneys, since if treatment appeared to be beneficial in this respect, there would be an argument in favour of screening. Chemotherapy was highly successful during the first 2 years, only 2 girls having remained persistently culture-positive. Nevertheless no significant difference was found in the renal growth rates in the treated and untreated groups in those girls whose kidneys were radiologically normal or showed only equivocal scarring at the start of the trial. Only one girl developed an unequivocal scar in a previously normal kidney. This supports previous suggestions ${ }^{69}$ that scars are generally present before age 4 years. It also confirms the findings of our previous study that there was no increase in the prevalence or degree of renal scarring with age in children with covert bacteriuria. Therefore, when the kidneys are radiologically normal, covert bacteriuria does not appear to lead to renal damage in the age groups studied, even if no treatment is given. It can therefore be concluded that a screening programme for the detection and treatment of covert bacteriuria does not benefit girls with radiologically normal kidneys over the time period studied.

However, the screening programme did detect 39 girls with renal scarring, who formed $0 \cdot 29 \%$ of the schoolgirl population. The scarring was severe in $7(0.05 \%)$ and in $14(0.10 \%)$ it was of moderate degree. The 21 girls with moderate to severe scarring and 9 with equivocal scarring were all in the OCG who were given a 2-year course of chemotherapy on ethical grounds. Twenty-six $(87 \%)$ of a total of 30 girls with renal scars who received chemotherapy were culture-negative at 5 years. Nevertheless, the radiological follow-up of these girls was less satisfactory with 21 out of 33 scarred kidneys showing poor growth and 8 patients showing increased scarring. There was clinical evidence of a definite response to treatment in one girl who had malignant hypertension with papilloedema when detected. All the girls in this group remained clinically well during the 5-year follow-up.

If a satisfactory non-invasive and non-radiographic method could be developed to detect girls with scarring, a screening programme solely to find girls with this condition would be desirable. However this is not yet available. A good correlation was shown in the previous report ${ }^{4}$ between a high serum antibody titre to the infecting organisms and renal scarring (18 of 38 ) but high levels were also found in an appreciable number without scarring. Further serum antibody tests during the follow-up detected raised levels in only 5 further girls with scarred kidneys bringing the total to 23 . This is essentially similar to the results reported by Smellie et al. ${ }^{10}$ in children with symptomatic disease and shows its serious limitations as a screening procedure. An immunofluorescent method to detect the presence of antibody-coated bacteria in the urine was evaluated in another study (to be reported) as a means of detecting upper urinary tract infections. However, only half the number of girls with renal scarring would have been detected using this method alone. The use of this method in conjunction with the serum antibody titre estimation did not increase the detection of renal scarring appreciably. Hellerstein et al. ${ }^{11}$ similarly found no significant correlation between the presence of antibody-coated bacteria in the urine and upper urinary tract infection in a group of 45 children.

The results of the present study support the essentially similar clinical and radiological findings of the 4-year follow-up of the Cardiff-Oxford Bacteriuria Study Group, ${ }^{6}$ which carried out a similar trial, but treated girls for periods of 2 weeks in most cases, but sometimes for up to one year. Savage et al. ${ }^{12}$ also failed to detect a clinically significant difference between treated and non-treated groups even though some symptomatic girls were included in their randomised groups. However their follow-up was only for 2 years and the numbers were small. 
Lindberg $e$ t al. ${ }^{13}$ who carried out a 3-year follow-up of 116 schoolgirls with bacteriuria, did not detect impaired renal growth or a decrease in renal concentrating capacity in girls who remained asymptomatic during the observation period. However 2 girls who developed symptomatic pyelonephritis showed renal scarring and parenchymal reduction.

Gillenwater et al..$^{14}$ studied the natural history of covert bacteriuria in 60 schoolgirls compared with 38 matched controls. The girls with bacteriuria received short courses of antimicrobial chemotherapy whenever necessary and after 9 to 18 years of follow-up there was evidence of higher morbidity from recurrent infections and symptomatic pyelonephritis in this group than in the control group. Bacteriuria during pregnancy was also more common. Although none of these girls reached endstage renal failure, 2 required nephrectomy and another had atrophic pyelonephritis with reduced inulin clearance. Many of the girls who deteriorated had normal radiological findings on initial examination. There was no evidence of the effectiveness of treatment. It is of interes $\hat{t}$ that there was also some evidence from the present study that 7 girls had developed radiological abnormalities or had impaired renal growth. However, this deterioration could not have been predicted from any of the initial assessments, nor was it any more frequent in those girls who did not receive chemotherapy.

On consideration of our results we conclude that, until a reliable, non-radiological technique to detect renal scarring is available, screening schoolgirls for covert bacteriuria should not be recommended. However, in view of the findings of Gillenwater et $a .^{14}$ it is possible that the more-prolonged follow-up of the girls in the present study may add further information and warrant reconsideration of this decision. The girls are still under surveillance and the results of 10 years' study of covert bacteriuria will be the subject of a further communication. This should be of particular interest, since many of the girls have now had at least one pregnancy.

We thank A Titchmarsh and B Whitehead (nurses), $\mathbf{J}$ Linkleter and $\mathbf{M}$ Turner (medical laboratory scientific officers), and J P Johnson (secretary) for their help.

This research project was supported by a grant from the Department of Health and Social Security (Grant JR/124/27); we are particularly appreciative of the support given by Dr J S Metters, liaison officer.

\section{References}

1 Brunner F P, Brynger H, Chantler C, et al. Combined report on regular dialysis and transplantation in Europe. IX Report 1978. Proc Eur Dial Transplant Assoc 1979; 16: 4-73.

2 Kunin C M, Zacha E, Paquin A J, Jr. Urinary-tract infections in school children: prevalence of bacteriuria and associated urologic findings. $N$ Engl J Med 1962; 266: 1287-96.

3 Asscher A W, McLachlan M S F, Verrier Jones E R, et al. Screening for asymptomatic urinary-tract infection in schoolgirls. Lancet 1973; ii: 1-4.

4 Newcastle Asymptomatic Bacteriuria Research Group. Asymptomatic bacteriuria in schoolchildren in Newcastleupon-Tyne. Newcastle Asymptomatic Bacteriuria Investigation: First Report, 1975. Arch Dis Child 1975; 50: 90-102.

5 Eklöf O, Ringertz H. Kidney size in children: a method of assessment. Acta Radiol [Diagn] (Stockh) 1976; 17: 617-25.

- Cardiff-Oxford Bacteriuria Study Group. Sequelae of covert bacteriuria in schoolgirls - a four-year follow-up study. Lancet 1978; i: 889-93.

7 Percival A, Brumfitt W, De Louvois J. Serum-antibody levels as an indication of clinically inapparent pyelonephritis. Lancet 1964; ii: 1027-33.

8 Claësson I, Lindberg U. Asymptomatic bacteriuria in schoolgirls. VII. A follow-up study of the urinary tract in treated and untreated schoolgirls with asymptomatic bacteriuria. Radiology 1977; 124: 179-83.

9 Hodson C J, Maling T M J, McManamon P J, Lewis M G. Reflux nephropathy. Kidney Int 1975; 8: Supplement 4, S50-8.

10 Smellie J M, Pursell R, Prescod N, Brumfitt W. Relationship between serum antibody titre and radiological findings in children with urinary tract infection. In: Brumfitt W, Asscher A W, eds. Urinary tract infection. Oxford: Oxford University Press, 1973: 31-8.

11 Hellerstein S, Kennedy E, Nussbaum L, Rice K. Localization of the site of urinary tract infections by means of antibody-coated bacteria in the urinary sediments. J Pediatr 1978; 92 : 188-93.

12 Savage D C L, Howie G, Adler K, Wilson M I. Controlled trial of therapy in covert bacteriuria of childhood. Lancet 1975; i: $358-61$.

13 Lindberg U, Claësson I, Hanson L Å, Jodal U. Asymptomatic bacteriuria in schoolgirls. VIII. Clinical course during a 3-year follow-up. J Pediatr 1978; 92: 194-9.

14 Gillenwater J Y, Harrison R B, Kunin C M. Natural history of bacteriuria in schoolgirls-a long-term casecontrol study. $N$ Engl J Med $1979 ; 301$ : 396-9.

${ }^{15}$ Simpson W, Cranage J D, Furness J A. Kidney size compared with intervertebral height. The importance of possible variation in normal values. Acta Radiol [Diagn] (Stockh) 1981 ; in press.

Correspondence to Dr J B Selkon, Regional Public Health Laboratory, Newcastle General Hospital, Westgate Road, Newcastle upon Tyne NE4 6BE.

Received 17 October 1980

See commentary on page 599. 